\title{
Early risk factors for adult bipolar disorder in adolescents with mood disorders: a 15-year follow-up of a community sample
}

\author{
Aivar Päären ${ }^{1 *}$, Hannes Bohman ${ }^{1}$, Lars von Knorring ${ }^{2}$, Gunilla Olsson ${ }^{1}$, Anne-Liis von Knorring ${ }^{1}$ and Ulf Jonsson ${ }^{1,2}$
}

\begin{abstract}
Background: We aimed to outline the early risk factors for adult bipolar disorder (BPD) in adolescents with mood disorders.

Methods: Adolescents (16-17 years old) with mood disorders ( $n=287 ; 90$ participants with hypomania spectrum episodes and 197 with major depressive disorder [MDD]) were identified from a community sample. Fifteen years later (at 30-33 years of age), mood episodes were assessed $(n=194)$. The risk of developing BPD $(n=22)$, compared with MDD $(n=104)$ or no mood episodes in adulthood $(n=68)$, was estimated via logistic regression. Adolescent mood symptoms, non-mood disorders, and family characteristics were assessed as potential risk factors.

Results: Among the adolescents with mood disorders, a family history of BPD was the strongest predictor of developing BPD compared with having no mood episodes in adulthood $(\mathrm{OR}=5.94 ; 95 \% \mathrm{Cl}=1.11-31.73)$, whereas disruptive disorders significantly increased the risk of developing BPD compared with developing MDD (OR $=2.94$; $\mathrm{Cl}=1.06-8.12)$. The risk that adolescents with MDD would develop adult BPD, versus having no mood episodes in adulthood, was elevated among those with an early disruptive disorder $(\mathrm{OR}=3.62 ; \mathrm{Cl}=1.09-12.07)$ or multiple somatic symptoms $(\mathrm{OR}=6.60 ; \mathrm{Cl}=1.70-25.67)$. Only disruptive disorders significantly predicted adult $\mathrm{BPD}$ among adolescents with MDD versus continued MDD in adulthood ( $\mathrm{OR}=3.59 ; \mathrm{Cl}=1.17-10.97)$. Only a few adolescents with hypomania spectrum episodes continued to have BPD as adults, and anxiety disorders appeared to increase this risk.

Conclusions: Although most of the identified potential risk factors are likely general predictors of continued mood disorders, disruptive disorders emerged as specific predictors of developing adult BPD among adolescents with MDD.
\end{abstract}

Keywords: Adolescent mood disorders, Bipolar disorder, Predictors, Long-term follow-up assessment

\section{Background}

Numerous studies have shown that adolescents with mood disorders are at an increased risk of continued mood disorders in early adulthood [1-10]. However, the presence of (hypo)manic symptoms during childhood and adolescence does not necessarily indicate a continuing course of bipolar disorder (BPD) in adulthood [11-14]. The early signs that predict the continued course of adolescent mood disorders are not well established. Thus, we do not know which

\footnotetext{
* Correspondence: aivar.paaren@neuro.uu.se

${ }^{1}$ Department of Neuroscience, Child and Adolescent Psychiatry, Uppsala University, Box 593, SE-75124 Uppsala, Sweden

Full list of author information is available at the end of the article
}

adolescents with a mood disorders will develop BPD, major depressive disorder (MDD), or neither as adults.

BPD is a severe condition associated with substantial impairments in emotional, cognitive, and social functioning [15-18]. An increased knowledge regarding the early signs of BPD might provide insight regarding the development of the mood disorder and help identify individuals at risk of developing BPD and enable early intervention.

Adolescent BPD is associated with early signs such as mood lability or swings, anxiety, hyperarousal, somatic complaints, behavioral dysregulation, attention difficulties and school problems [5,18-22]. Several studies have

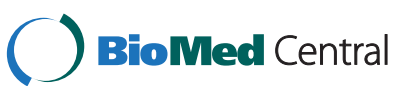

(c) 2014 Päären et al.; licensee BioMed Central. This is an Open Access article distributed under the terms of the Creative Commons Attribution License (http://creativecommons.org/licenses/by/4.0), which permits unrestricted use, distribution, and reproduction in any medium, provided the original work is properly credited. The Creative Commons Public Domain Dedication waiver (http://creativecommons.org/publicdomain/zero/1.0/) applies to the data made available in this article unless otherwise stated. 
investigated whether the early signs of psychopathology predict BPD later in life. Numerous studies have demonstrated high rates of developing mania among children or adolescents with depression [23-28]. Therefore, earlyonset depressive symptoms or MDD might predict later BPD. Disruptive behavioral disorders, in combination with mood changes, have been identified as more specific markers of the early onset of BPD [5,27,29-32]. In addition, previous authors have found that the presence of anxiety disorders, especially panic disorder, might be a marker of the early onset of BPD [7,33-35].

Still, the best-established early marker of BPD risk remains family history $[14,36,37]$. This factor has been widely accepted in clinical practice, despite the fact that the majority of the high-risk offspring of individuals with mood disorders do not develop BPD [38-41]. However, a large proportion of offspring develop other mental disorders [42].

The clinical usefulness of the early markers/premorbid problems as predictors of subsequent BPD has not been proven. The generally high frequency of pre-morbidities and comorbidities between adolescent mood disorders, externalizing disorders and internalizing disorders raises questions regarding the relevance of these disorders for the continued disease course.

To summarize, conclusive findings within this area of research are sparse and additional research is needed. The present study is based on a unique community sample of adolescents with mood disorders, followed up after 15 years. Although previous publications form this cohort have not focused on the potential risk factors of BPD, certain results have indicated that specific factors might be important. We have shown that long-term adolescent depression strongly predicts both continued MDD and BPD in adulthood [10]. In another publication, we reported that multiple somatic symptoms in adolescence independently predict both continued MDD and BPD in adulthood $[43,44]$. Depressed adolescents with more than four somatic symptoms had particularly poor outcomes, with high rates of severe, recurrent, and chronic depression or BPD. Somewhat surprisingly, we also found, that adolescents with hypomania spectrum episodes did not have a higher risk of BPD in adulthood compared with those with only MDD [14]. On the other hand, a family history of BPD appears to predict BPD in adulthood. Adolescents with either hypomania spectrum disorder or MDD, who also had a $1^{\text {st }}$ - and/or $2^{\text {nd }}$ - degree family member with BPD, were more likely to have BPD as adults compared with those without this history. Adolescents with MDD and a $1^{\text {st }}$ - and/or $2^{\text {nd }}$ - degree relative with BPD were more likely to develop BPD versus those with MDD and no such history. Similarly, adolescents with hypomania spectrum disorder tended to have (hypo)mania episode(s) in adulthood if they had a $1^{\text {st }}$ - and/or $2^{\text {nd }}$ - degree family member with BPD.
The present study includes a range of potential child and adolescent risk factors for developing BPD. Our overarching aim was to identify the early risk factors of adult BPD (compared with MDD or no mood episodes in adulthood) among individuals with adolescent mood episodes. We investigated the potential risk factors for the following:

a) adult BPD among individuals with previous mood episodes (either MDD or hypomania spectrum episodes) during adolescence;

b) the development of adult BPD among those with adolescent hypomania spectrum episodes; and

c) the development of adult BPD among those with adolescent MDD.

\section{Methods}

\section{Study design and participants}

This study examined the early risk factors for BPD in a high-risk community sample of adolescents with mood disorders. The data were prospectively collected in two waves, with a baseline assessment at age 16-17 years of age and a blinded follow-up assessment at 30-33 years of age (see Figure 1). We assessed adolescent risk factors for BPD at the follow-up assessment compared with 1) MDD in adulthood and 2) no mood episodes in adulthood.

Detailed methods of this community-based study have been published elsewhere [10,14,45]. Briefly, 2,300 of 2,446 (93\%) 16 - to 17 -year-olds in a mid-sized Swedish community participated in a screening procedure aimed at identifying individuals with depressive symptoms using the Beck Depression Inventory-Child (BDI-C) $[46,47]$ and the Centre for Epidemiological Studies - Depression Scale for Children (CES-DC) [48-50]. Students with positive screenings (BDI $\geq 16$, CES-DC $\geq 30+\mathrm{BDI} \geq 11$, or a previous suicide attempt) were interviewed using the revised form of the Diagnostic Interview for Children and Adolescents according to the DSM-III-R for adolescents (DICAR-A) [51]. For each student with a positive screening, a same-sex classmate with a negative screening was interviewed in the same manner. In total, 631 adolescents were interviewed and invited to consent to a follow-up study.

In the present study, participants with a DICA-R-A diagnosis of MDD ( $n=197)$, a hypomania spectrum episode $(n=90)$, or both at the first evaluation (i.e., $16-17$ years of age) were included. A hypomania spectrum episode was defined as having an "elevated mood", "grandiosity" or both and at least 1-3 additional manic symptoms or irritability as the only core symptom and at least 4 additional manic symptoms. The participants either met the criteria for full syndromal hypomania $(n=40)$ or brief-episode hypomania (less than four days of symptoms; $\mathrm{n}=18$ ) or subsyndromal hypomania (1 or 2 core 


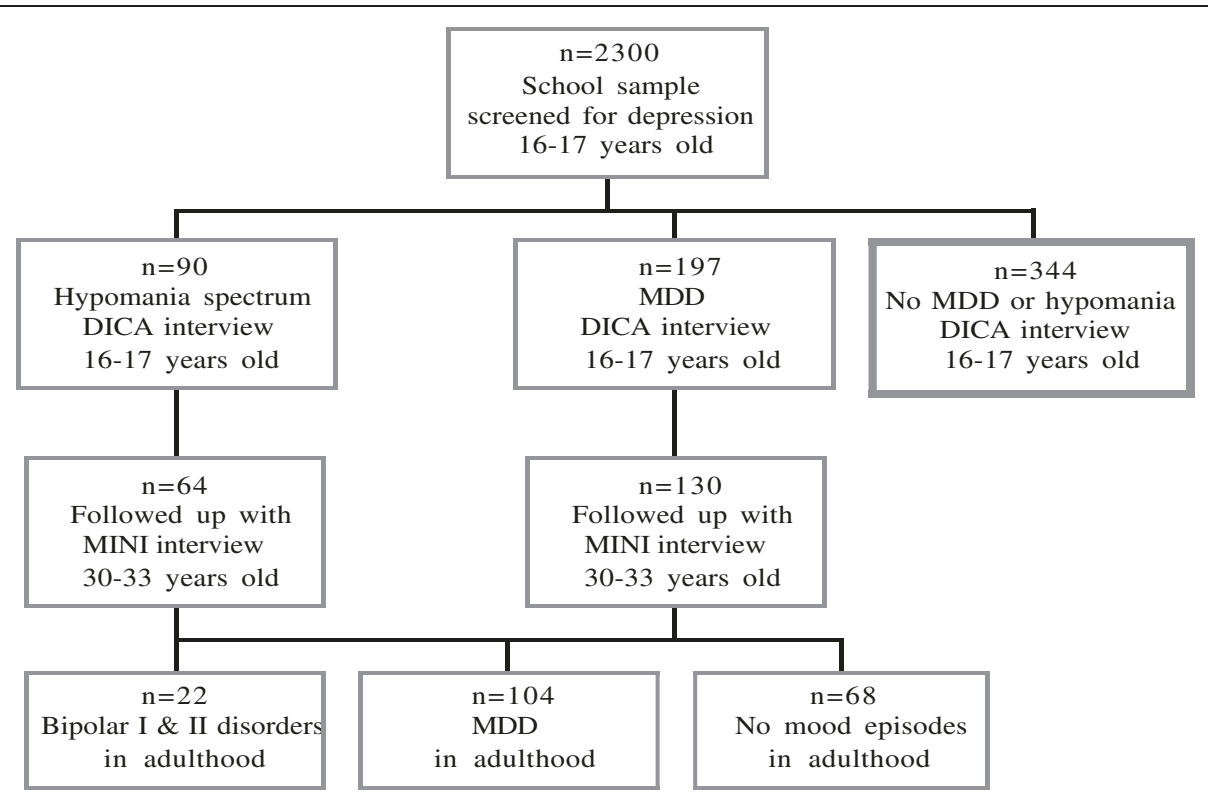

Figure 1 Chart illustrating the selection of participants and division into groups for the present study. Note: Of the 2300 adolescents originally screened for depression, participants with positive screening and an equal number of peers with negative screening, were diagnostically interviewed.

symptoms and 1-2 additional symptoms were fullfilled) $(\mathrm{n}=32)$. The majority had also experienced a major depressive episode $(n=68) ; 10$ participants had subthreshold depression and twelve had no depression.

To ensure that the symptoms were not better explained by ADHD, we determined that the 12 participants in the hypomania group without depression did not meet the criteria for ADHD.

\section{Procedure}

At baseline, the participants were assessed using the DICA-R-A. The participants also completed numerous self-rating scales, including the Somatic Checklist Instrument (SCI) [52]. A psychiatrist conducted more than half of the interviews, while staff trained by this psychiatrist (two psychiatric nurses, two psychologists, and a student) conducted the rest of the interviews. In order to ascertain inter-rater reliability simultaneous scoring were done in 27 interviews, with only minor discrepancies between the raters.

A follow-up assessment was conducted after 15 years, when the participants were 30-33 years of age. A blinded assessment of adult mental disorders was conducted with the Mini International Neuropsychiatric Interview Plus [53]. Episodes of major depression, hypomania and mania were rated between age 19 and the follow-up assessment. To enhance participant recall of mood episodes during the investigated period, a life-chart with questions concerning life events, mood episodes, and treatments was used. In addition, information regarding family histories of mood disorders in $1^{\text {st }}$ - and/or $2^{\text {nd }}$ - degree relatives were collected at the follow-up assessment. The five interviewers, trained in clinical psychology or psychiatry, were blinded to the information from the baseline evaluation. To enhance inter-rater reliability, each interviewer was video-recorded once, and the recorded interviews were rated by all interviewers. These recordings yielded an overall free-marginal kappa value of 0.93. To further increase reliability, and to ensure the clinical validity of the diagnoses, uncertainties were regularly discussed with senior psychiatrists during sessions of group supervision.

All participants $(n=194)$ with an adolescent mood disorder who participated in the follow-up evaluation were included in the analyses. The participants with a diagnosis of bipolar I or II disorder in adulthood were compared with those with MDD and those with no mood episodes in adulthood with regard to potential risk factors.

\section{Potential risk factors}

Several risk factors with potential relevance for the continued course of mood disorder were considered in the analyses, including child and adolescent mental disorders, adolescent mood symptoms, somatic symptoms, adverse life events during childhood and adolescence, and a family history of mood disorders in $1^{\text {st }}$ - and/or $2^{\text {nd }}$ - degree relatives.

Previous and current child and adolescent mental disorders as well as psychotic and affective symptoms were recorded using the DICA-R-A. The following diagnoses 
were included in the analyses: separation anxiety; avoidant disorder (social phobia); overanxiousness (GAD); panic disorder; obsessive-compulsive disorder (OCD); posttraumatic stress disorder (PTSD); eating disorders (i.e., anorexia nervosa and bulimia nervosa); disruptive disorders (i.e., conduct disorder [CD], oppositional defiant disorder [ODD] or attention-deficit/hyperactivity disorder [ADHD]); and substance abuse (drugs, glue or alcohol).

In addition, long-term depression among adolescents was included as a predictor in the analyses because previous analyses showed that this variable strongly predicts continued mood disorders [10]. Long-term depression was defined as major depression during most of the previous year, major depression followed by symptoms meeting the criteria for dysthymia, or major depression superimposed on a state of dysthymia.

Childhood psychotic symptoms, other than schizophrenia, concerned present or previous delusional symptoms or hallucinations that were not due to the direct physiological effects of a substance (e.g., drug abuse and medication) were included in the analyses.

The included adolescent hypomanic symptoms were elevated mood, grandiosity, irritability, distractibility, increased activity, racing thoughts, pressured speech and a decreased need for sleep. The depressive episode symptoms were suicide attempt, suicide ideation, dysphoria, anhedonia, psychomotor inhibition, fatigue, feelings of worthlessness, problems with concentration, and sleep and appetite disturbances. Details regarding the mood symptoms recorded in this cohort have been published previously [14].

The presence of multiple somatic symptoms was included as a potential risk factor because previous analyses have shown that these symptoms predict continued mood episodes $[43,44]$. The SCI assesses various physical symptoms via 22 items [54]. Each symptom was graded with regard to frequency ( $0=$ never, $1=$ monthly, $2=$ weekly, $3=$ several times a week, and $4=$ daily $)$ and intensity $(0=$ no problem, $1=$ minor, $2=$ moderate, $3=$ troublesome, and 4 = extremely troublesome). The present study categorized a somatic symptom as such when its frequency and intensity were multiplied, and a score $\geq 6$ was obtained (e.g., $2 \times 3$ : weekly and troublesome symptoms). This categorization excluded the possibility that monthly premenstrual symptoms were recorded as somatic symptoms. Multiple somatic symptoms were defined as 5 or more symptoms.

The DICA-R-A [51] also included questions regarding adverse life events during adolescence. Items regarding family histories of substance abuse, family violence and deaths in the family due to an accident were selected. Details of the baseline characteristics have been published previously $[49,55]$.
At the follow-up assessment, the participants reported their family histories of depressive episodes or manic/ hypomanic episodes among their $1^{\text {st }}$ - or $2^{\text {nd }}$ - degree relatives (i.e., parents, siblings, children, grandparents, uncles, aunts, nephews, nieces, and half-siblings).

\section{Antidepressant treatment in childhood, adolescence and adulthood}

Antidepressant medication has been reported to trigger (hypo)manic episodes in some patients. We used information from both the baseline assessment and the follow-up interview in order to ascertain that the (hypo) manic episodes reported were not attributable to medication: Treatments during childhood and adolescence were assessed with the DICA-R-A, and no participant reported psychotropic medication. At follow-up, the MINI interview was used to identify mood episodes and a life-chart was used to indicate when mood episodes had occurred and when the individual had received treatment for the mood episodes. Of the 22 participants reporting bipolar disorder in adulthood, 14 reported treatment with antidepressants. However, all these 14 participants reported that the first (hypo) manic episode had occurred before the antidepressant treatment was introduced.

\section{Follow-up attrition}

The participation rate at the follow-up evaluation was $66 \%(130 / 197)$ among those with adolescent MDD and $71 \%$ (64/90) among those with adolescent hypomania spectrum episodes. No major differences were identified between those who participated and those who were lost to follow up. Details regarding the follow-up attrition have been published previously [45].

\section{Statistical analyses}

In the first set of analyses, adolescents with MDD or hypomania spectrum episodes were divided into three groups: those who developed BPD in adulthood; those who developed MDD in adulthood; or those who did not developed mood episodes in adulthood (Table 1). Differences in risk factors (previous diagnoses, clinical characteristics and family characteristics) were analyzed using a univariate logistic regression. In the second step, statistically significant risk factors were entered as covariates into multivariate logistic regression models. In the first model, the outcome variable was BPD versus no mood episodes in adulthood. In the second model, the outcome variable was BPD versus MDD in adulthood.

The risk factors that differed significantly between those who developed adult BPD and those who did not have mood episodes in adulthood were used to calculate a receiver operating characteristic (ROC) curve to evaluate 
Table 1 Potential child and adolescent risk factors of adult bipolar disorder (BPD) compared with major depression disorder (MDD) or no mood episodes in adulthood

\begin{tabular}{|c|c|c|c|c|c|}
\hline \multirow{3}{*}{$\begin{array}{l}\text { Potential risk factors in } \\
\text { childhood/adolescence }\end{array}$} & \multirow{2}{*}{$\begin{array}{l}\text { A } \\
\text { BPD in } \\
\text { adulthood }\end{array}$} & \multirow{2}{*}{$\begin{array}{l}\text { B } \\
\text { MDD in } \\
\text { adulthood }\end{array}$} & \multirow{2}{*}{$\begin{array}{l}\text { C } \\
\text { No mood episode } \\
\text { in adulthood }\end{array}$} & \multirow{3}{*}{$\begin{array}{l}\text { A vs. C } \\
\text { OR }(95 \% \mathrm{Cl})\end{array}$} & \multirow{3}{*}{$\begin{array}{l}\text { A vs. B } \\
\text { OR }(95 \% \mathrm{Cl})\end{array}$} \\
\hline & & & & & \\
\hline & $n=22(\%)$ & $n=104(\%)$ & $\mathrm{n}=68(\%)$ & & \\
\hline Female & $19(86)$ & $87(84)$ & $51(75)$ & $2.11(0.56-8.03)$ & $1.24(0.33-4.65)$ \\
\hline \multicolumn{6}{|l|}{ Mental disorders (DICA-R-A): } \\
\hline Separation Anxiety disorder & $10(46)$ & $40(39)$ & $20(29)$ & $2.00(0.75-5.37)$ & $1.33(0.53-3.37)$ \\
\hline Social Phobia & $2(9)$ & $17(16)$ & $9(13)$ & $0.66(0.13-3.29)$ & $0.51(0.11-2.40)$ \\
\hline GAD & $8(36)$ & $47(45)$ & $14(21)$ & $2.20(0.77-6.29)$ & $0.69(0.27-1.79)$ \\
\hline Panic Disorder & $5(23)$ & $16(15)$ & $5(7)$ & $3.71(0.96-14.30)$ & $1.62(0.52-5.01)$ \\
\hline Any anxiety disorder ${ }^{a}$ & $15(68)$ & $71(68)$ & $35(52)$ & $2.02(0.73-5.58)$ & $1.00(0.37-2.67)$ \\
\hline OCD & $4(18)$ & $27(26)$ & $12(18)$ & $1.04(0.30-3.62)$ & $0.63(0.20-2.04)$ \\
\hline PTSD & - & $6(6)$ & - & - & - \\
\hline Eating disorders & $2(9)$ & $5(5)$ & $4(6)$ & $1.60(0.27-9.39)$ & $1.98(0.36-10.93)$ \\
\hline Disruptive disorder (CD/ODD/ADHD) & $13(59)$ & $30(29)$ & $20(29)$ & $3.47(1.28-9.40)^{*}$ & $3.56(1.38-9.21)^{* *}$ \\
\hline Substance abuse & $3(14)$ & $10(10)$ & $8(12)$ & $1.18(0.29-4.92)$ & $1.47(0.37-5.85)$ \\
\hline \multicolumn{6}{|l|}{ Mania episode symptoms: } \\
\hline Elevated mood & $5(23)$ & $34(33)$ & $25(37)$ & $0.51(0.17-1.54)$ & $0.61(0.21-1.78)$ \\
\hline Grandiosity & $7(32)$ & $35(34)$ & $29(43)$ & $0.63(0.23-1.74)$ & $0.92(0.34-2.46)$ \\
\hline Irritability & $2(9)$ & $7(7)$ & $4(6)$ & $1.60(0.27-9.39)$ & $1.39(0.27-7.17)$ \\
\hline Distractibility & $1(5)$ & $14(14)$ & $9(13)$ & $0.31(0.04-2.61)$ & $0.31(0.04-2.46)$ \\
\hline Increased activity & $6(27)$ & $31(30)$ & $19(28)$ & $0.97(0.33-2.84)$ & $0.88(0.32-2.47)$ \\
\hline Racing thoughts & $4(18)$ & $18(17)$ & $9(13)$ & $1.46(0.40-5.30)$ & $1.06(0.32-3.51)$ \\
\hline Pressured speech & $3(14)$ & $21(20)$ & $12(18)$ & $0.74(0.19-2.89)$ & $0.62(0.17-2.31)$ \\
\hline Decreased need of sleep & $5(23)$ & $33(32)$ & $23(34)$ & $0.58(0.19-1.76)$ & $0.63(0.22-1.86)$ \\
\hline \multicolumn{6}{|l|}{ Depressive episode symptoms: } \\
\hline Suicide attempt & $4(18)$ & $25(24)$ & $15(22)$ & $0.79(0.23-2.68)$ & $0.70(0.22-2.27)$ \\
\hline Suicide ideation & $15(68)$ & $63(61)$ & $35(51)$ & $1.55(0.57-4.18)$ & $1.37(0.53-3.50)$ \\
\hline Dysphoria & $20(91)$ & $99(95)$ & $63(93)$ & $0.79(0.14-4.41)$ & $0.51(0.91-2.79)$ \\
\hline Anhedonia & $17(77)$ & $80(77)$ & $41(60)$ & $2.24(0.74-6.79)$ & $1.02(0.34-3.05)$ \\
\hline Psychomotor inhibition & $18(82)$ & $79(76)$ & $49(72)$ & $1.75(0.52-5.83)$ & $1.42(0.44-4.60)$ \\
\hline Fatigue & $15(68)$ & $82(79)$ & $47(69)$ & $0.96(0.34-2.69)$ & $0.58(0.21-1.58)$ \\
\hline Worthlessness & $20(91)$ & $84(81)$ & $43(63)$ & $5.81(1.25-26.98)^{*}$ & $2.38(0.51-11.03)$ \\
\hline Trouble concentration & $18(82)$ & $82(79)$ & $53(78)$ & $1.27(0.37-4.34)$ & $1.21(0.37-3.93)$ \\
\hline Sleep disturbances & $12(55)$ & $52(50)$ & $32(47)$ & $1.35(0.51-3.54)$ & $1.20(0.48-3.02)$ \\
\hline Appetite disturbances & $18(82)$ & $83(80)$ & $49(72)$ & $1.75(0.52-5.83)$ & $1.14(0.35-3.72)$ \\
\hline Psychotic symptoms & $2(9)$ & $6(6)$ & $3(4)$ & $2.17(0.34-13.89)$ & $1.63(0.31-8.69)$ \\
\hline Somatic symptoms $(\geq 5)^{b}$ & $11(50)$ & $30(31)$ & $11(17)$ & $4.82(1.67-13.88)^{* *}$ & $2.27(0.89-5.80)$ \\
\hline Long-term depression ${ }^{c}$ & $14(64)$ & $54(52)$ & $23(34)$ & $3.42(1.26-9.34)^{*}$ & $1.62(0.63-4.19)$ \\
\hline \multicolumn{6}{|l|}{ Family characteristics: } \\
\hline Substance abuse in family & $3(14)$ & $12(12)$ & $5(7)$ & $1.99(0.44-9.10)$ & $1.20(0.31-4.66)$ \\
\hline Violence in family & $7(32)$ & $19(18)$ & $15(22)$ & $1.65(0.57-4.78)$ & $2.06(0.74-5.76)$ \\
\hline Death in family by accident & $4(18)$ & $23(22)$ & $13(19)$ & $0.94(0.27-3.25)$ & $0.77(0.24-2.51)$ \\
\hline
\end{tabular}


Table 1 Potential child and adolescent risk factors of adult bipolar disorder (BPD) compared with major depression disorder (MDD) or no mood episodes in adulthood (Continued)

\begin{tabular}{|c|c|c|c|c|c|}
\hline Family history of BPD ${ }^{d}$ & $5(23)$ & $8(8)$ & $3(4)$ & $6.37(1.38-29.36)^{*}$ & $3.53(1.03-12.08)^{*}$ \\
\hline Family history of MDD ${ }^{d}$ & $15(68)$ & $71(68)$ & $25(37)$ & $3.69(1.32-10.27)^{*}$ & $0.99(0.37-2.67)$ \\
\hline Family history of BPD or MDD ${ }^{d}$ & $16(73)$ & $71(68)$ & $27(40)$ & $4.05(1.41-11.65)^{* *}$ & $1.24(0.44-3.46)$ \\
\hline
\end{tabular}

${ }^{a}$ Separation Anxiety disorder, Social Phobia, GAD, or Panic Disorder.

${ }^{\mathrm{b}}$ The number of individuals who completed the MINI interview and the SCL for somatic symptoms differed slightly (In the MDD group there are missing data for six persons and in the no-mood episode group for four persons).

${ }^{\mathrm{C}}$ Long-term depression was defined as major depression during most of the previous year, major depression followed by symptoms meeting the criteria for dysthymia, or major depression superimposed on a state of dysthymia.

${ }^{d} 1^{\text {st }}$ and/or $2^{\text {nd }}$ degree family history of BPD and/or MDD.

MDD: Major depressive disorder; OCD: Obsessive-compulsive disorder; PTSD: Posttraumatic stress disorder; ADHD: Attention-deficit/hyperactivity disorder; CD: Conduct disorder; ODD: Oppositional defiant disorder; GAD: Generalized anxiety disorder. Note: * $p<0.05 ;{ }^{* *} p<0.01$.

the sensitivity and specificity for numerous risk factors. The calculation of a ROC curve for the risk factors of BPD versus MDD in adulthood was not possible because of the low number of significant risk factors.

All analyses were first adjustment for sex. This adjustment did not change the results and was not included in the final analyses presented in the results section. In the second set of analyses, univariate logistic regressions were used to identify the risk factors for adult BPD separately for the adolescents with MDD and the adolescents with hypomania spectrum episodes. Multivariate analyses were not conducted because of the smaller sample sizes of these groups. P-values below 0.05 were considered statistically significant for all statistical analyses. IBM SPSS Statistics version 22.0 for Macintosh was used.

\section{Ethics}

The Regional Ethical Vetting Board of Uppsala, Sweden approved this study, which was conducted in accordance with the ethical standards established in the Declaration of Helsinki. Both written and verbal information about the study was offered to the students (16-17 years). Informed consent to be contacted for a future follow-up evaluation was also collected. At age 30-33 years, the participants who had given their consent to be contacted were sent written information about the follow-up evaluation. Before consenting to take part, the participants were also informed about the study verbally via telephone. The Regional Ethical Vetting Board approved the verbal consent procedure used in the study.

\section{Results}

\section{Risk factors for adult BPD among all adolescents with} mood disorders

Of the 194 participants with adolescent mood disorders who were followed up after 15 years, 22 were diagnosed with bipolar I or II, 104 had MDD and 68 had no mood episodes in adulthood. The results of the univariate logistic regression analyses of the risk factors for BPD in adulthood (versus having MDD or no mood episodes) are presented in Table 1. Disruptive disorders significantly increased the risk of BPD compared with MDD $(\mathrm{OR}=3.56 ; 95 \% \mathrm{CI}=1.38-9.21)$ and no mood episodes $(\mathrm{OR}=3.47 ; \mathrm{CI}=1.28-9.40)$. In addition $1^{\text {st }}-$ and $/$ or $2^{\text {nd }}$ degree family histories of BPD significantly increased the risk of adult BPD compared with having MDD (OR = 3.53; $\mathrm{CI}=1.03-12.08)$ or no mood episodes in adulthood $(\mathrm{OR}=6.37$; $\mathrm{CI}=1.38-29.36)$.

The feeling of worthlessness was the single affective symptom from the DICA-interview that significantly increased the risk of BPD compared with not having a mood episode. The other significant risk factors for adult BPD (compared with no mood episodes in adulthood) included multiple somatic symptoms $(\mathrm{OR}=4.82 ; \mathrm{CI}=$ 1.67-13.88), and long-term depression $(\mathrm{OR}=4.38 ; \mathrm{CI}=$ 1.39-13.80). A history of child and adolescent panic disorder was not a significant risk factor $(\mathrm{OR}=3.71 ; \mathrm{CI}=$ 0.96-14.30). Similarly, a history of any anxiety disorder (Separation Anxiety disorder, Social Phobia, GAD, or Panic Disorder) in childhood and adolescence did not reach statistical significance as a risk factor for adult bipolar disorder compared with having no mood episodes $(\mathrm{OR}=2.02 ; \mathrm{CI}=0.73-5.58)$ or $\mathrm{MDD}(\mathrm{OR}=1.00 ; \mathrm{CI}=$ $0.37-2.67)$ in adulthood.

The following independent risk factors were entered in multivariate logistic regression analyses: disruptive disorders; feelings of worthlessness; multiple somatic symptoms; long-term depression; and $1^{\text {st }}$ - and/or $2^{\text {nd }}$ degree family histories of BPD. In this model, three risk factors remained significant for adult BPD compared with no mood episodes: feelings of worthlessness (OR = $5.20 ; C I=1.01-27.08) ; 1^{\text {st }}$ - and/or $2^{\text {nd }}$ - degree family histories of $\mathrm{BPD}(\mathrm{OR}=5.94 ; \mathrm{CI}=1.11-31.73)$; and multiple somatic symptoms $(\mathrm{OR}=3.33 ; \mathrm{CI}=1.04-10.72])$. The same five risk factors for adult BPD (compared with no mood episodes) were evaluated using an ROC curve (Figure 2). The presence of at least two risk factors resulted in a sensitivity of $68 \%$ and specificity of $72 \%$, whereas the presence of three or more risk factors resulted in sensitivity of $52 \%$ and specificity of $88 \%$. 


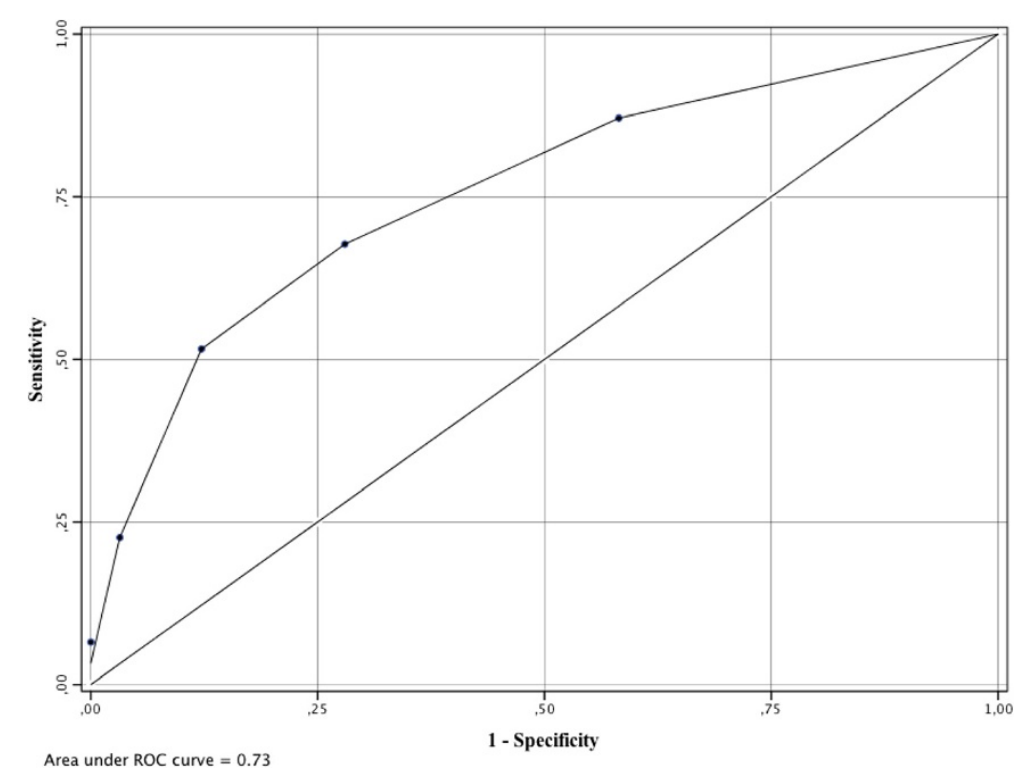

Figure 2 The receiver operating characteristic (ROC) curve of adult bipolar disorder (compared with no mood episodes in adulthood) among adolescents with mood disorders, according to the number of five independent child and adolescent risk factors. The following risk factors were included: disruptive disorders; feelings of worthlessness; multiple somatic symptoms; long-term depression; 1st and/or 2nd degree family histories of bipolar disorder. The presence of at least two risk factors resulted in a sensitivity of $68 \%$ and specificity of $72 \%$, whereas the presence of three or more risk factors resulted in sensitivity of $52 \%$ and specificity of $88 \%$.

Only disruptive disorders significantly increased the risk of BPD compared with MDD in a multivariate analysis using the same five risk factors $(\mathrm{OR}=2.94 ; \mathrm{CI}=1.06-8.12)$.

\section{Risk factors for adult BPD among adolescents with hypomania spectrum episodes}

Of the 64 adolescents with hypomania spectrum episodes during childhood, 6 had developed adult hypomania or mania, 32 developed MDD and 26 reported no mood episodes in adulthood.

The continuity between adolescent hypomania spectrum and adult BPD (compared with no mood episode) was associated with panic disorder $(\mathrm{OR}=12.00$; $\mathrm{CI}=1.39$ 103.48), GAD $(\mathrm{OR}=12.00 ; \mathrm{CI}=1.39-103.48)$ and longterm depression $(\mathrm{OR}=12.00 ; \mathrm{CI}=1.39-103.48)$. When these three factors were entered simultaneously into a logistic regression analysis, panic disorder and GAD predicted an increased risk of adult BPD, whereas long-term depression did not remain as significant (Figure 3). A trend was also observed for an increased risk of continued adult BPD (compared with having no mood disorder) with regard to the presence of $1^{\text {st }}$ - and/or $2^{\text {nd }}$ - degree family histories of $\mathrm{BPD}(\mathrm{OR}=12.50 ; \mathrm{CI}=0.91-172.08)$ and the $1^{\text {st }}$ - and/or $2^{\text {nd }}-$ degree family histories of MDD (OR = 9.44; $\mathrm{CI}=0.95-93.64$ ).

Continuity between adolescent hypomania spectrum and adult BPD (compared with MDD in adulthood) was associated with psychotic symptoms in adolescence $(\mathrm{OR}=15.50$; $\mathrm{CI}=1.13-212.18$; Figure 4).
Risk factors for developing adult BPD among adolescents with MDD

Out of the 130 adolescents with MDD during adolescence, 72 developed adult MDD, 16 developed hypomania or mania and 42 reported no mood episodes in adulthood. The transition from adolescent MDD to adult BPD (compared with no mood episodes in adulthood) was associated with the presence of disruptive disorders $(\mathrm{OR}=3.62 ; \mathrm{CI}=1.09-12.07)$ and multiple somatic symptoms $(\mathrm{OR}=6.60 ; \mathrm{CI}=1.70-25.67$; Figure 3$)$. A trend was observed for the increased risk of BPD with regard to $1^{\text {st }}$-and/or $2^{\text {nd }}$ - degree family histories of BPD or MDD $(\mathrm{OR}=3.24 ; \mathrm{CI}=0.95-11.00)$.

The transition from adolescent MDD to adult BPD (compared with continuing MDD in adulthood) was only significantly associated with adolescent disruptive disorders $(\mathrm{OR}=3.59$; $\mathrm{CI}=1.17-10.97$; Figure 4$)$.

\section{Discussion}

This study analyzed unique data from a prospective 15year follow-up community sample of adolescents with mood disorders to identify the early risk factors for adult BPD. Numerous child and adolescent factors differed between those who developed BPD and those who did not have any mood episodes in adulthood, including family histories of BPD, multiple somatic symptoms, and anxiety disorders. Disruptive disorder in childhood or adolescence as well as family histories of BPD emerged as significant risk factors that differentiated between the future 


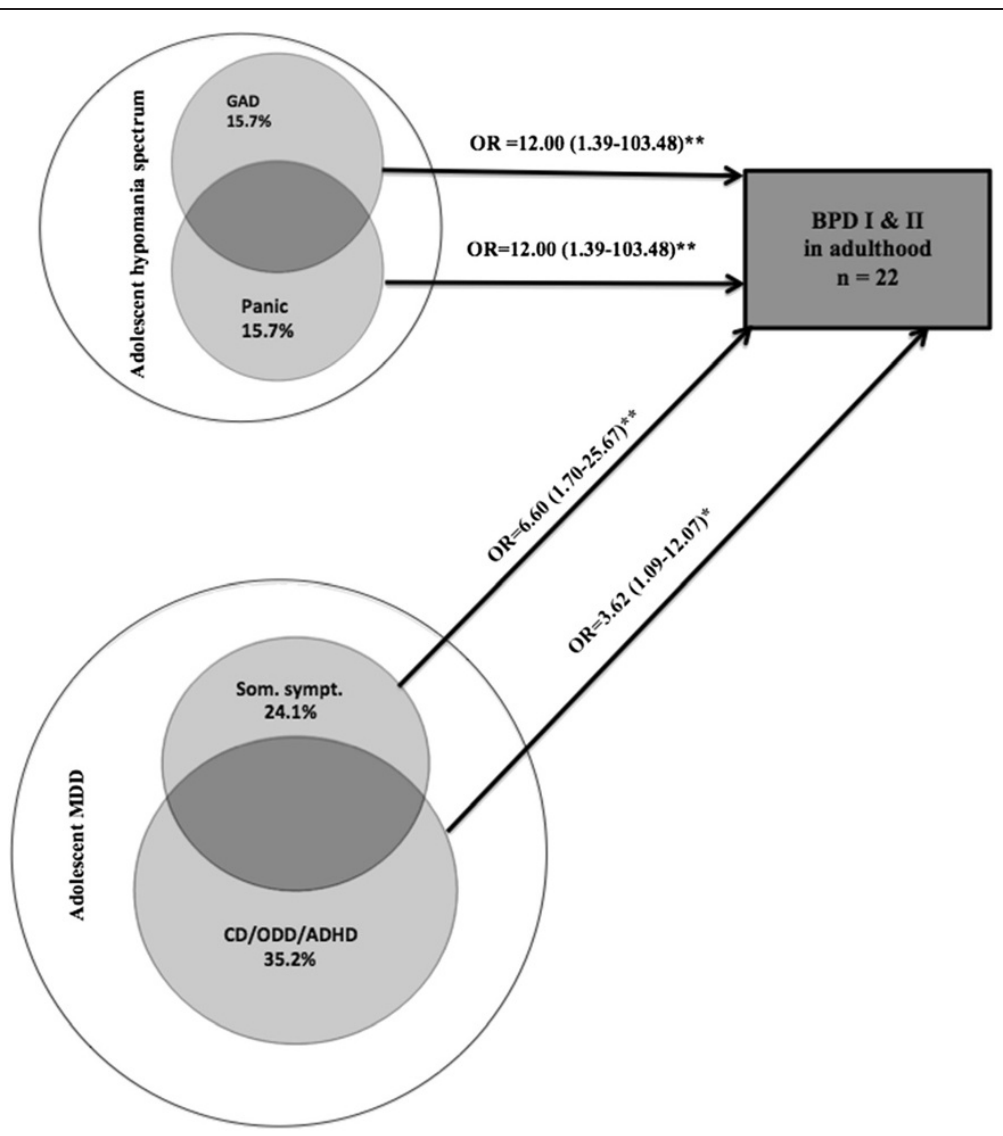

Figure 3 Child and adolescent risk factors for developing bipolar disorder (BPD; $n=22$ ) compared with no mood episodes ( $n=68$ ) in adulthood among adolescents with hypomania spectrum episodes $(n=32 ; 6$ developed adult BPD) or transition from adolescent MDD to adult BPD ( $\mathbf{n}=\mathbf{5 8} ; \mathbf{1 6}$ developed adult BPD). Note: ${ }^{*} p<0.05 ;{ }^{* *} p<0.01$.

development of BPD and MDD. However, no predictor clearly delineated the group of adolescents who subsequently developed BPD as adults.

Our results are in line with previous studies showing that a family history of BPD is a robust risk factor for this disorder [23,27,36,37,56-61]. This finding is also consistent with genetic-epidemiological and genome-wide linkage studies [62-64]. However, specific predictors have been difficult to determine within high-risk offspring populations $[25,27,40,58,65,66]$. This difficulty might be partially explained by the fact that previous studies have not differentiated between the continuity of (hypo)mania symptoms during childhood and adolescence into adult BPD or the transition from adolescent MDD to adult BPD. In addition, the genetic heterogeneity of BPD might influence its different trajectories; therefore, different subtypes of BPD might exist and further differentiation studies are needed.

Our results are also in keeping with previous studies suggesting that anxiety disorders are significant predictors of bipolar spectrum disorders. These studies indicate that anxiety disorders precede the onset of BPDs in general $[7,40,67-71]$, or frequently overlap with BPDs [72-74]. Our results highlight panic disorder and GAD as potential risk factors for continued BPD among adolescents with hypomania spectrum. Several studies have suggested that panic disorder shares genetic and family histories with BPD $[34,35,75,76]$. Panic disorder is often associated with BPD rapid cycling [77], as are disruptive disorders $[78,79]$.

The presence of a disruptive disorder was the only factor associated with the transition from adolescent MDD to adult BPD (compared with continuation of MDD). Several longitudinal studies have found an association between early disruptive disorders and the bipolar spectrum $[30,31,40,80]$. Both disruptive disorders and BPD are associated with a low threshold for arousal and related to high emotional reactivity. It is possible that disruptive behavioral features and bipolar symptoms may be part of a continuum, and disruptive behavioral symptoms may serve as an early marker of BPD $[5,20,30,81,82]$. However, a previous high-risk offspring study concluded that behavioral disorders are not a specific predictor of BPD; rather the risk of having this condition seems to be elevated among 


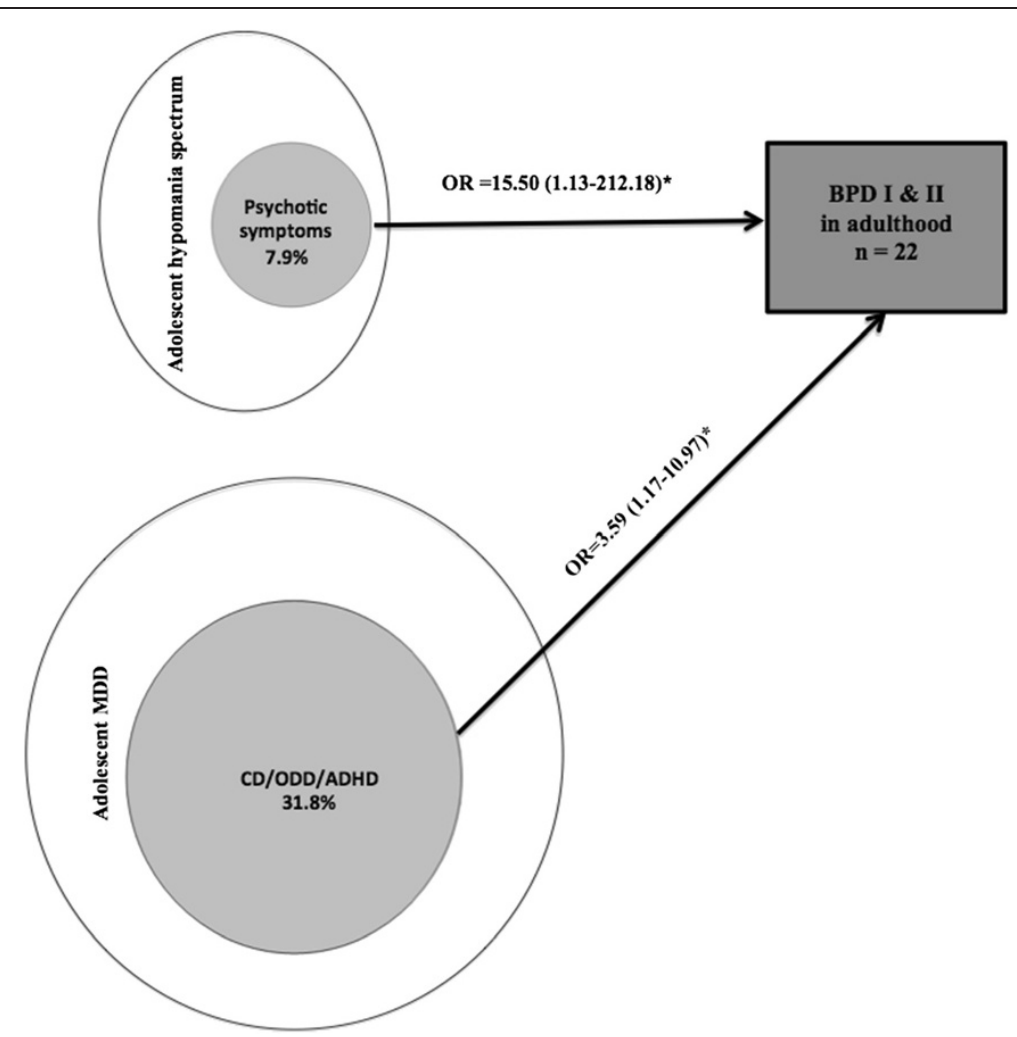

Figure 4 Child and adolescent risk factors for developing bipolar disorder (BPD; $\mathbf{n}=22$ ) compared with major depressive disorder (MDD; $n=104$ ) in adulthood among adolescents with hypomania spectrum episodes ( $n=38 ; 6$ developed adult BPD) or transition from adolescent MDD to adult BPD ( $\mathbf{n}=\mathbf{8 8} ; \mathbf{1 6}$ developed adult BPD). Note: ${ }^{*} p<0.05$.

subgroups of offspring with parents with BPD who did not respond to lithium $[27,40,65]$. It is possible that disruptive disorders are not only comorbid to BPD, but might also precede bipolar disorders or even represent an early stage of the disorder.

Different types of risk factors predominated among adolescents with MDD who developed adult BPD and those with hypomania spectrum episodes who developed adult BPD. Disruptive disorders, multiple somatic symptoms (somatic complaints), or both precede adolescent MDD before developing adult BPD. Furthermore, panic disorder, GAD or both were associated with adolescent hypomania before developing adult BPD. It is possible that these two predictor groups might represent different developmental trajectories of adult BPD. The first subtype, which is preceded by disruptive disorders, somatic symptoms (somatic complaints) or both, appears to overlap with characteristics of irritability, explosive anger, aggression, mood lability and somatic complaints, which are criteria for the cyclothymic temperament $[2,83,84]$. Furthermore, unstable personality features such as cyclothymic temperament and borderline personality disorder, are more common among patients with BPD than among patients with unipolar depression [84-90]. On the other hand, the second subtype, represented by anxiety disorders, might be best viewed as an expression of a general vulnerability factor for mood disorders rather than a bipolar-specific risk factor. Our findings also show that anxiety disorders can precede adult BPD, which is in line with previous studies $[2,35,58,59,91]$.

Psychotic symptoms might play a similar role. Among adolescents with a hypomania spectrum disorder, early psychotic symptoms appeared to increase the risk of BPD in adulthood. However, psychotic symptoms only occurred in a few individuals, and these results should be interpreted with caution. Early psychotic symptoms that lead to later mood disorders are more clearly aligned with BPD than unipolar depressive disorders [91-93]. This association is also in line with previous studies emphasizing the role of the psychotic features related to early onset mood disorder and the increased risk of BPDs or schizoaffective disorder in long-term follow-up studies [94-100].

Thus, psychotic symptoms in childhood and adolescence probably have diagnostic and prognostic values. Progressive brain changes might occur after the first psychotic/depressive episode, resulting in the inadequate maturation of the cortex [101-108] and provoking mild but progressive brain dysfunction with cognitive impairments in participants with bipolar disorder [103,109-112]. More research is needed on this topic. 


\section{Clinical considerations}

Although no predictor of high sensitivity or specificity was identified, the results may still have important implications for clinical practice. In the present study, $11.3 \%$ of the participants developed adult BPD. This rate was substantially higher in subsamples with the major identified risk factors, including $31.3 \%$ of participants with family histories of BPD, $20.6 \%$ of participants with disruptive disorders, and $19.2 \%$ of participants with panic disorder. However, none of the studied predictors had specificity or sensitivity values high enough to be used in routine clinical practice with regard to informing patients and their families of the supposed long-term course of the disorder or facilitating decisions on the long-term use of mood stabilizers. However, given the serious nature of BPD and recurrent MDD, adolescents with mood disorders and, in particular, those with early indications of an increased risk for future BPD should be followed up with carefully, preferably in specialized affective disorder subunits, where the long-term results are best $[113,114]$.

\section{Strengths and limitations}

This study has numerous strengths. The study was based on a large, well-defined community sample, and it focused on the natural development of mood disorders. Participants were assessed during adolescence and followed up 15 years later by clinically trained interviewers blinded to the adolescent interviews. We had access to extensive data about mood episodes, other mental disorders, and treatment. Of note, no case of suspected antidepressant induced switch was identified in this sample, although we had data on the timing of mood episodes and antidepressant treatment.

Certain limitations of this study must also be considered. First, the participants lost to follow-up might have more severe mood disorders. However, separate analyses demonstrated that those lost to follow-up and those who participated did not differ substantially with regard to adolescent psychopathology [14,45,115]. Furthermore, the complete sample has been followed in Swedish national registers data [116]. The registers indicated that only few individuals had been treated for BPD, which suggests that we did not miss many severe cases.

Second, although we included both adolescents with MDD and hypomania spectrum episodes, the original community study was designed to screen for only depression and not for hypomania. No hypomania screening measurement was used at the baseline evaluation, and therefore some individuals with ongoing hypomania might not have been identified. A fully representative sample of adolescents with hypomania spectrum episodes might show a slightly different result. However, 317 controls with negative screening results were also diagnostically interviewed. In addition, numerous studies have demonstrated that the early onset of depressive disorders in children or adolescents typically precedes BPD $[3,23,24,27,40,117,118]$. It should also be noted that no hypomania rating scale was used at follow-up. Although all participants at this stage were diagnostically interviewed, a rating scale could have added a dimensional perspective.

Third, there are some potential limitations regarding to the validity of our data. All information was selfreported. Further, we did not include potential predictors such as socioeconomic status and gender. Finally, a general risk of type II errors exists, because of the relatively small number of participants. Larger samples are needed in future studies.

\section{Conclusion}

The current results provide an overview of a range of potential clinical risk factors of adult BPD among adolescents with mood disorders. No risk factor of high sensitivity or specificity was identified. Because of the severity of BPD, however, adolescents with mood disorders should be followed carefully into adulthood. Characteristics such as family histories, disruptive disorders, anxiety disorders, somatic symptoms, and family histories of mood disorders warrant particular attention. In order to make progress, it is likely that future studies need to include larger samples and account for both genetic factors and psychosocial exposure during critical periods.

\section{Abbreviations}

DSM-IV: American Psychiatric Association Diagnostic and Statistical Manual of Mental Disorders; DICA: Diagnostic Interview for Children and Adolescents in the Revised form According to DSM-III-R for Adolescents; BDI-C: Beck Depression Inventory-Child; CES-DC: Centre for Epidemiological Studies Depression Scale for Children; MINI: Mini International Neuropsychiatric Interview Plus; BPD: Bipolar disorder; SCl: The Somatic Checklist Instrument; MDD: Major depression disorder; OCD: Obsessive-compulsive disorder; ADHD: Attention-deficit/hyperactivity disorder; CD: Conduct disorder; ODD: Oppositional defiant disorder; PTSD: Posttraumatic stress disorder; GAD: Overanxiousness; ROC curve: Receiver operating characteristic curve.

\section{Competing interests}

The authors declare that they have no competing interests.

\section{Authors' contributions}

AP had the original idea for this study, had primary responsibility for the data analysis, and drafted and revised the manuscript. UJ had primary responsibility for the data collection in the follow-up phase of the study, supervised the design and execution of the study, and contributed to the conception, analyses and interpretation of the data and to the revision of the manuscript. A-LvK supervised the design and execution of the study, and contributed to the conception, analyses and interpretation of the data and to the revision of the manuscript. GO had primary responsibility for the patient screening and enrollment in the baseline study, and contributed to the conception of the study, the analyses and interpretation of the data and to the revision of the manuscript. $\mathrm{HB}$ contributed to the conception of the study, the analyses and interpretation of the data and to the revision of the manuscript. LvK contributed to the conception of the study, the analyses and interpretation of the data and to the revision of the manuscript. All authors read and approved the final manuscript. 


\section{Acknowledgements}

We greatly appreciate Hans Arinell for his valuable statistical advice and assistance.

\section{Role of funding source}

The Swedish Council for Working Life and Social Research (FAS) and the Foundation in Memory of Professor Bror Gadelius financially supported this work.

\section{Author details}

'Department of Neuroscience, Child and Adolescent Psychiatry, Uppsala University, Box 593, SE-75124 Uppsala, Sweden. ${ }^{2}$ Department of Neuroscience, Psychiatry, Uppsala University, Akademiska sjukhuset, SE-751 85 Uppsala, Sweden.

Received: 22 September 2014 Accepted: 11 December 2014 Published online: 24 December 2014

\section{References}

1. Akiskal HS, Downs J, Jordan P, Watson S, Daugherty D, Pruitt DB: Affective disorders in referred children and younger siblings of manic-depressives. Mode of onset and prospective course. Arch Gen Psychiatry 1985, 42(10):996-1003.

2. Akiskal HS: Developmental pathways to bipolarity: are juvenile-onset depressions pre-bipolar? J Am Acad Child Adolesc Psychiatry 1995, 34(6):754-763

3. Strober M, Schmidt-Lackner S, Freeman R, Bower S, Lampert C, DeAntonio $M$ : Recovery and relapse in adolescents with bipolar affective illness: a five-year naturalistic, prospective follow-up. J Am Acad Child Adolesc Psychiatry 1995, 34(6):724-731.

4. Kovacs M: Presentation and course of major depressive disorder during childhood and later years of the life span. J Am Acad Child Adolesc Psychiatry 1996, 35(6):705-715.

5. Wozniak J, Biederman J, Kiely K, Ablon JS, Faraone SV, Mundy E, Mennin D: Mania-like symptoms suggestive of childhood-onset bipolar disorder in clinically referred children. J Am Acad Child Adolesc Psychiatry 1995, 34(7):867-876

6. Geller B, Tillman R, Craney JL, Bolhofner K: Four-year prospective outcome and natural history of mania in children with a prepubertal and early adolescent bipolar disorder phenotype. Arch Gen Psychiatry 2004, 61(5):459-467.

7. Johnson JG, Cohen P, Brook JS: Associations between bipolar disorder and other psychiatric disorders during adolescence and early adulthood: a community-based longitudinal investigation. Am J Psychiatry 2000, 157(10):1679-1681.

8. Fergusson DM, Horwood LJ, Ridder EM, Beautrais AL: Subthreshold depression in adolescence and mental health outcomes in adulthood. Arch Gen Psychiatry 2005, 62(1):66-72.

9. Fergusson DM, Boden JM, Horwood LJ: Recurrence of major depression in adolescence and early adulthood, and later mental health, educational and economic outcomes. Br J Psychiatry 2007, 191:335-342.

10. Jonsson U, Bohman H, von Knorring L, Olsson G, Paaren A, von Knorring AL: Mental health outcome of long-term and episodic adolescent depression: 15-year follow-up of a community sample. J Affect Disord 2011, 130(3):395-404.

11. Lewinsohn PM, Klein DN, Seeley JR: Bipolar disorder during adolescence and young adulthood in a community sample. Bipolar Disord 2000, 2(3 Pt 2):281-293.

12. Lewinsohn PM, Shankman SA, Gau JM, Klein DN: The prevalence and co-morbidity of subthreshold psychiatric conditions. Psychol Med 2004, 34(4):613-622.

13. Tijssen MJ, van Os J, Wittchen HU, Lieb R, Beesdo K, Mengelers R, Wichers $\mathrm{M}$ : Prediction of transition from common adolescent bipolar experiences to bipolar disorder: 10-year study. Br J Psychiatry 2010, 196(2):102-108.

14. Paaren $A$, von Knorring $A L$, Olsson $G$, von Knorring $L$, Bohman $H$, Jonsson $U$ : Hypomania spectrum disorders from adolescence to adulthood: a 15-year follow-up of a community sample. J Affect Disord 2013, 145(2):190-199.

15. Skjelstad DV, Malt UF, Holte A: Symptoms and signs of the initial prodrome of bipolar disorder: a systematic review. J Affect Disord 2010, 126(1-2):1-13.
16. Luby JL, Navsaria N: Pediatric bipolar disorder: evidence for prodromal states and early markers. J Child Psychol Psychiatry 2010, 51(4):459-471.

17. Rucklidge JJ: Retrospective parent report of psychiatric histories: do checklists reveal specific prodromal indicators for postpubertal-onset pediatric bipolar disorder? Bipolar Disord 2008, 10(1):56-66.

18. Egeland JA, Hostetter AM, Pauls DL, Sussex JN: Prodromal symptoms before onset of manic-depressive disorder suggested by first hospital admission histories. J Am Acad Child Adolesc Psychiatry 2000, 39(10):1245-1252.

19. Geller B, Zimerman B, Williams M, Delbello MP, Frazier J, Beringer L: Phenomenology of prepubertal and early adolescent bipolar disorder: examples of elated mood, grandiose behaviors, decreased need for sleep, racing thoughts and hypersexuality. J Child Adolesc Psychopharmacol 2002, 12(1):3-9.

20. Fergus EL, Miller RB, Luckenbaugh DA, Leverich GS, Findling RL, Speer AM, Post RM: Is there progression from irritability/dyscontrol to major depressive and manic symptoms? A retrospective community survey of parents of bipolar children. J Affect Disord 2003, 77(1):71-78.

21. Egeland JA, Shaw JA, Endicott J, Pauls DL, Allen CR, Hostetter AM, Sussex JN: Prospective study of prodromal features for bipolarity in well Amish children. J Am Acad Child Adolesc Psychiatry 2003, 42(7):786-796.

22. Chang K, Steiner H, Dienes K, Adleman N, Ketter T: Bipolar offspring: a window into bipolar disorder evolution. Biol Psychiatry 2003, 53(11):945-951.

23. Angst J, Sellaro R, Stassen HH, Gamma A: Diagnostic conversion from depression to bipolar disorders: results of a long-term prospective study of hospital admissions. J Affect Disord 2005, 84(2-3):149-157.

24. Hillegers $M H$, Reichart CG, Wals M, Verhulst FC, Ormel J, Nolen WA: Five-year prospective outcome of psychopathology in the adolescent offspring of bipolar parents. Bipolar Disord 2005, 7(4):344-350.

25. Birmaher B, Axelson D, Monk K, Kalas C, Goldstein B, Hickey MB, Obreja M, Ehmann M, lyengar S, Shamseddeen W, Kupfer D, Brent D: Lifetime psychiatric disorders in school-aged offspring of parents with bipolar disorder: the Pittsburgh Bipolar Offspring study. Arch Gen Psychiatry 2009, 66(3):287-296.

26. Conus P, Ward J, Hallam KT, Lucas N, Macneil C, McGorry PD, Berk M: The proximal prodrome to first episode mania-a new target for early intervention. Bipolar Disord 2008, 10(5):555-565.

27. Duffy A: Does bipolar disorder exist in children? A selected review. Can J Psychiatry 2007, 52(7):409-417.

28. Strober M, Lampert C, Schmidt S, Morrell W: The course of major depressive disorder in adolescents: I. Recovery and risk of manic switching in a follow-up of psychotic and nonpsychotic subtypes. J Am Acad Child Adolesc Psychiatry 1993, 32(1):34-42.

29. Biederman J, Russell R, Soriano J, Wozniak J, Faraone SV: Clinical features of children with both ADHD and mania: does ascertainment source make a difference? J Affect Disord 1998, 51(2):101-112.

30. Kim-Cohen J, Caspi A, Moffitt TE, Harrington H, Milne BJ, Poulton R: Prior juvenile diagnoses in adults with mental disorder: developmental follow-back of a prospective-longitudinal cohort. Arch Gen Psychiatry 2003, 60(7):709-717.

31. Hirshfeld-Becker DR, Biederman J, Henin A, Faraone SV, Cayton GA, Rosenbaum JF: Laboratory-observed behavioral disinhibition in the young offspring of parents with bipolar disorder: a high-risk pilot study. Am J Psychiatry 2006, 163(2):265-271.

32. Tijssen MJ, Van Os J, Wittchen HU, Lieb R, Beesdo K, Wichers M: Risk factors predicting onset and persistence of subthreshold expression of bipolar psychopathology among youth from the community. Acta Psychiatr Scand 2010, 122(3):255-266.

33. Wozniak J, Biederman J, Monuteaux MC, Richards J, Faraone SV: Parsing the comorbidity between bipolar disorder and anxiety disorders: a familial risk analysis. J Child Adolesc Psychopharmacol 2002, 12(2):101-111.

34. Birmaher B, Kennah A, Brent D, Ehmann M, Bridge J, Axelson D: Is bipolar disorder specifically associated with panic disorder in youths? J Clin Psychiatry 2002, 63(5):414-419.

35. Diler RS, Birmaher B, Brent DA, Axelson DA, Firinciogullari S, Chiapetta L, Bridge J: Phenomenology of panic disorder in youth. Depress Anxiety 2004, 20(1):39-43.

36. Birmaher B, Axelson D, Goldstein B, Strober M, Gill MK, Hunt J, Houck P, Ha W, lyengar S, Kim E, Yen S, Hower H, Esposito-Smythers C, Goldstein T, Ryan $\mathrm{N}$, Keller M: Four-year longitudinal course of children and adolescents 
with bipolar spectrum disorders: the Course and Outcome of Bipolar Youth (COBY) study. Am J Psychiatry 2009, 166(7):795-804.

37. Fiedorowicz JG, Endicott J, Leon AC, Solomon DA, Keller MB, Coryell WH: Subthreshold hypomanic symptoms in progression from unipolar major depression to bipolar disorder. Am J Psychiatry 2011, 168(1):40-48.

38. Duffy A, Grof P, Robertson C, Alda M: The implications of genetics studies of major mood disorders for clinical practice. J Clin Psychiatry 2000, 61(9):630-637.

39. Duffy A, Doucette S, Lewitzka U, Alda M, Hajek T, Grof P: Findings from bipolar offspring studies: methodology matters. Early Interv Psychiatry 2011, 5(3):181-191.

40. Duffy A, Horrocks J, Doucette S, Keown-Stoneman C, McCloskey S, Grof P: The developmental trajectory of bipolar disorder. Br J Psychiatry 2014, 204(2):122-128.

41. Grof P, Alda M: Discrepancies in the efficacy of lithium. Arch Gen Psychiatry 2000, 57(2):191.

42. Rasic D, Hajek T, Alda M, Uher R: Risk of mental illness in offspring of parents with schizophrenia, bipolar disorder, and major depressive disorder: a meta-analysis of family high-risk studies. Schizophr Bull 2014, 40(1):28-38

43. Bohman $\mathrm{H}$, Jonsson $U$, Von Knorring AL, Von Knorring L, Paaren A, Olsson G: Somatic symptoms as a marker for severity in adolescent depression. Acta Paediatr 2010, 99(11):1724-1730.

44. Bohman H, Jonsson U, Paaren A, von Knorring L, Olsson G, von Knorring AL: Prognostic significance of functional somatic symptoms in adolescence: a 15-year community-based follow-up study of adolescents with depression compared with healthy peers. BMC Psychiatry 2012, 12:90.

45. Paaren $A$, Bohman $H$, von Knorring $A L$, von Knorring $L$, Olsson $G$, Jonsson $U$ : Hypomania spectrum disorder in adolescence: a 15-year follow-up of non-mood morbidity in adulthood. BMC Psychiatry 2014, 14:9.

46. Beck AT, Ward CH, Mendelson M, Mock J, Erbaugh J: An inventory for measuring depression. Arch Gen Psychiatry 1961, 4:561-571.

47. Larsson B, Melin L: Depressive symptoms in Swedish adolescents. J Abnorm Child Psychol 1990, 18(1):91-103.

48. Schoenbach VJ, Kaplan BH, Grimson RC, Wagner EH: Use of a symptom scale to study the prevalence of a depressive syndrome in young adolescents. Am J Epidemiol 1982, 116(5):791-800.

49. Olsson G: Adolescent depression. Epidemiology, nosology, life stress and social network. Minireview based on a doctoral thesis. Ups J Med Sci 1998, 103(2):77-145.

50. Olsson G, von Knorring AL: Depression among Swedish adolescents measured by the self-rating scale Center for Epidemiology StudiesDepression Child (CES-DC). Eur Child Adolesc Psychiatry 1997, 6(2):81-87.

51. Reich W, Herjanic B, Welner Z, Gandhy PR: Development of a structured psychiatric interview for children: agreement on diagnosis comparing child and parent interviews. J Abnorm Child Psychol 1982, 10(3):325-336.

52. Lewis DW, Middlebrook MT, Mehallick L, Rauch TM, Deline C, Thomas EF: Pediatric headaches: what do the children want? Headache 1996, 36(4):224-230

53. Sheehan DV, Lecrubier $Y$, Sheehan $\mathrm{KH}$, Amorim $\mathrm{P}$, Janavs J, Weiller $\mathrm{E}$ Hergueta T, Baker R, Dunbar GC: The Mini-International Neuropsychiatric Interview (M.I.N.I.): the development and validation of a structured diagnostic psychiatric interview for DSM-IV and ICD-10. J Clin Psychiatry 1998, 59(Suppl 20):22-33. quiz 34-57.

54. Larsson BS: Somatic complaints and their relationship to depressive symptoms in Swedish adolescents. J Child Psychol Psychiatry 1991, 32(5):821-832.

55. Olsson Gl, von Knorring AL: Adolescent depression: prevalence in Swedish high-school students. Acta Psychiatr Scand 1999, 99(5):324-331.

56. Axelson DA, Birmaher B, Strober MA, Goldstein BI, Ha W, Gill MK, Goldstein TR, Yen S, Hower H, Hunt Jl, Liao F, lyengar S, Dicksen D, Kim E, Ryan ND, Frankel E, Keller MB: Course of subthreshold bipolar disorder in youth: diagnostic progression from bipolar disorder not otherwise specified. J Am Acad Child Adolesc Psychiatry 2011, 50(10):1001-1016 e1003.

57. Pavuluri MN, Birmaher B, Naylor MW: Pediatric bipolar disorder: a review of the past 10 years. J Am Acad Child Adolesc Psychiatry 2005, 44(9):846-871.

58. Duffy A: The early natural history of bipolar disorder: what we have learned from longitudinal high-risk research. Can J Psychiatry 2010 55(8):477-485.
59. Duffy A: The early course of bipolar disorder in youth at familial risk J Can Acad Child Adolesc Psychiatry 2009, 18(3):200-205.

60. Benazzi F: Bipolar family history of the hypomanic symptoms and dimensions of mixed depression. Compr Psychiatry 2005, 46(6):399-404

61. Akiskal HS: The bipolar spectrum-the shaping of a new paradigm in psychiatry. Curr Psychiatry Rep 2002, 4(1):1-3.

62. Sullivan PF, de Geus EJ, Willemsen G, James MR, Smit JH, Zandbelt T, Arolt V, Baune BT, Blackwood D, Cichon S, Coventry WL, Domschke K, Farmer A, Fava M, Gordon SD, He Q, Heath AC, Heutink P, Holsboer F, Hoogendijk WJ, Hottenga JJ, Hu Y, Kohli M, Lin D, Lucae S, Macintyre DJ, Maier W, McGhee KA, McGuffin P, Montgomery GW, et al: Genome-wide association for major depressive disorder: a possible role for the presynaptic protein piccolo. Mol Psychiatry 2009, 14(4):359-375.

63. Ferreira MA, O'Donovan MC, Meng YA, Jones IR, Ruderfer DM, Jones $L$, Fan J, Kirov G, Perlis RH, Green EK, Smoller JW, Grozeva D, Stone J, Nikolov I, Chambert K, Hamshere ML, Nimgaonkar VL, Moskvina V, Thase ME, Caesar S, Sachs GS, Franklin J, Gordon-Smith K, Ardlie KG, Gabriel SB, Fraser C, Blumenstiel B, Defelice M, Breen G, Gill M, et al: Collaborative genomewide association analysis supports a role for ANK3 and CACNA1C in bipolar disorder. Nat Genet 2008, 40(9):1056-1058.

64. Craddock N, Forty L: Genetics of affective (mood) disorders. Eur J Hum Genet 2006, 14(6):660-668.

65. Duffy A: The nature of the association between childhood ADHD and the development of bipolar disorder: a review of prospective high-risk studies. Am J Psychiatry 2012, 169(12):1247-1255.

66. Birmaher B, Goldstein BI, Axelson DA, Monk K, Hickey MB, Fan J, lyengar S, Ha W, Diler RS, Goldstein T, Brent D, Ladouceur CD, Sakolsky D, Kupfer DJ: Mood lability among offspring of parents with bipolar disorder and community controls. Bipolar Disord 2013, 15(3):253-263.

67. Azorin JM, Kaladjian A, Adida M, Fakra E, Hantouche E, Lancrenon S: Baseline and prodromal characteristics of first- versus multiple-episode mania in a French cohort of bipolar patients. Eur Psychiatry 2012, 27(8):557-562.

68. Duffy A, Horrocks J, Doucette S, Keown-Stoneman C, McCloskey S, Grof P: Childhood anxiety: an early predictor of mood disorders in offspring of bipolar parents. J Affect Disord 2013, 150(2):363-369.

69. Duffy A, Alda M, Hajek T, Sherry SB, Grof P: Early stages in the development of bipolar disorder. J Affect Disord 2010, 121(1-2):127-135.

70. Henin A, Biederman J, Mick E, Hirshfeld-Becker DR, Sachs GS, Wu Y, Yan L, Ogutha J, Nierenberg AA: Childhood antecedent disorders to bipolar disorder in adults: a controlled study. J Affect Disord 2007, 99(1-3):51-57.

71. Sala R, Axelson DA, Castro-Fornieles J, Goldstein TR, Ha W, Liao F, Gill MK, lyengar S, Strober MA, Goldstein BI, Yen S, Hower H, Hunt J, Rayan ND, Dickstein D, Keller MB, Birmaher B: Comorbid anxiety in children and adolescents with bipolar spectrum disorders: prevalence and clinical correlates. J Clin Psychiatry 2010, 71(10):1344-1350.

72. Quinn CA, Fristad MA: Defining and identifying early onset bipolar spectrum disorder. Curr Psychiatry Rep 2004, 6(2):101-107.

73. Azorin JM, Kaladjian A, Adida M, Hantouche EG, Hameg A, Lancrenon S, Akiskal HS: Psychopathological correlates of lifetime anxiety comorbidity in bipolar I patients: findings from a French national cohort. Psychopathology 2009, 42(6):380-386.

74. Vieta E, Colom F, Martinez-Aran A, Benabarre A, Reinares M, Gasto C: Bipolar II disorder and comorbidity. Compr Psychiatry 2000, 41(5):339-343.

75. Mackinnon DF, Xu J, McMahon FJ, Simpson SG, Stine OC, McInnis MG, DePaulo JR: Bipolar disorder and panic disorder in families: an analysis of chromosome 18 data. Am J Psychiatry 1998, 155(6):829-831.

76. MacKinnon DF, Zandi PP, Cooper J, Potash JB, Simpson SG, Gershon E, Nurnberger J, Reich T, DePaulo JR: Comorbid bipolar disorder and panic disorder in families with a high prevalence of bipolar disorder. Am J Psychiatry 2002, 159(1):30-35.

77. Coryell W, Endicott J, Keller M: Rapidly cycling affective disorder. Demographics, diagnosis, family history, and course. Arch Gen Psychiatry 1992, 49(2):126-131.

78. Mick E, Biederman J, Faraone SV, Murray K, Wozniak J: Defining a developmental subtype of bipolar disorder in a sample of nonreferred adults by age at onset. J Child Adolesc Psychopharmacol 2003, 13(4):453-462.

79. Findling RL, Gracious BL, McNamara NK, Youngstrom EA, Demeter CA Branicky LA, Calabrese JR: Rapid, continuous cycling and psychiatric co-morbidity in pediatric bipolar I disorder. Bipolar Disord 2001, 3(4):202-210. 
80. Merikangas KR, Akiskal HS, Angst J, Greenberg PE, Hirschfeld RM, Petukhova M, Kessler RC: Lifetime and 12-month prevalence of bipolar spectrum disorder in the National Comorbidity Survey replication. Arch Gen Psychiatry 2007, 64(5):543-552.

81. Meyer SE, Carlson GA, Wiggs EA, Martinez PE, Ronsaville DS, Klimes-Dougan B, Gold PW, Radke-Yarrow M: A prospective study of the association among impaired executive functioning, childhood attentional problems, and the development of bipolar disorder. Dev Psychopathol 2004, 16(2):461-476

82. Singh MK, DelBello MP, Kowatch RA, Strakowski SM: Co-occurrence of bipolar and attention-deficit hyperactivity disorders in children. Bipolar Disord 2006, 8(6):710-720.

83. Kochman FJ, Hantouche EG, Ferrari P, Lancrenon S, Bayart D, Akiskal HS: Cyclothymic temperament as a prospective predictor of bipolarity and suicidality in children and adolescents with major depressive disorder. $J$ Affect Disord 2005, 85(1-2):181-189.

84. Akiskal HS: Subaffective disorders: dysthymic, cyclothymic and bipolar II disorders in the "borderline" realm. Psychiatr Clin North Am 1981, 4(1):25-46.

85. Akiskal HS, Kilzieh N, Maser JD, Clayton PJ, Schettler PJ, Traci Shea M, Endicott J, Scheftner W, Hirschfeld RM, Keller MB: The distinct temperament profiles of bipolar I, bipolar II and unipolar patients. $J$ Affect Disord 2006, 92(1):19-33.

86. Hantouche EG, Akiskal HS: Toward a definition of a cyclothymic behavioral endophenotype: which traits tap the familial diathesis for bipolar II disorder? J Affect Disord 2006, 96(3):233-237.

87. van Valkenburg C, Kluznik JC, Speed N, Akiskal HS: Cyclothymia and labile personality: is all folie circulaire? J Affect Disord 2006, 96(3):177-181.

88. Perugi G, Ceraudo G, Vannucchi G, Rizzato S, Toni C, Dell'Osso L: Attention deficit/hyperactivity disorder symptoms in Italian bipolar adult patients: a preliminary report. J Affect Disord 2013, 149(1-3):430-434.

89. Perugi G, Angst J, Azorin JM, Bowden C, Vieta E, Young AH, Group BS: The bipolar-borderline personality disorders connection in major depressive patients. Acta Psychiatr Scand 2013, 128(5):376-383.

90. Benazzi F: Borderline personality-bipolar spectrum relationship. Prog Neuropsychopharmacol Biol Psychiatry 2006, 30(1):68-74.

91. Owoeye O, Kingston T, Scully PJ, Baldwin P, Browne D, Kinsella A, Russell V, O'Callaghan E, Waddington JL: Epidemiological and clinical characterization following a first psychotic episode in major depressive disorder: comparisons with schizophrenia and bipolar I disorder in the Cavan-Monaghan First Episode Psychosis Study (CAMFEPS). Schizophr Bull 2013, 39(4):756-765.

92. Weissman MM, Warner $V$, John K, Prusoff BA, Merikangas KR, Wickramaratne P, Gammon GD: Delusional depression and bipolar spectrum: evidence for a possible association from a family study of children. Neuropsychopharmacology 1988, 1(4):257-264.

93. Goes FS, Sadler B, Toolan J, Zamoiski RD, Mondimore FM, Mackinnon DF Schweizer B, Bipolar Disorder Phenome G, Raymond Depaulo J Jr, Potash JB: Psychotic features in bipolar and unipolar depression. Bipolar Disord 2007, 9(8):901-906.

94. Nicolson R, Lenane M, Brookner F, Gochman P, Kumra S, Spechler L, Giedd JN, Thaker GK, Wudarsky M, Rapoport JL: Children and adolescents with psychotic disorder not otherwise specified: a 2- to 8-year follow-up study. Compr Psychiatry 2001, 42(4):319-325.

95. Salvatore P, Baldessarini RJ, Tohen M, Khalsa HM, Sanchez-Toledo JP, Zarate CA Jr, Vieta E, Maggini C: McLean-Harvard International First-Episode Project: two-year stability of DSM-IV diagnoses in 500 first-episode psychotic disorder patients. J Clin Psychiatry 2009, 70(4):458-466.

96. Salvatore P, Baldessarini RJ, Khalsa HM, Amore M, Di Vittorio C, Ferraro G, Maggini $C$, Tohen M: Predicting diagnostic change among patients diagnosed with first-episode DSM-IV-TR major depressive disorder with psychotic features. J Clin Psychiatry 2013, 74(7):723-731. quiz 731

97. Salvatore P, Baldessarini RJ, Khalsa HM, Vazquez G, Perez J, Faedda GL, Amore M, Maggini C, Tohen M: Antecedents of manic versus other first psychotic episodes in 263 bipolar I disorder patients. Acta Psychiatr Scand 2014, 129(4):275-285.

98. Baldessarini RJ, Bolzani L, Cruz N, Jones PB, Lai M, Lepri B, Perez J, Salvatore $P$, Tohen $M$, Tondo $L$, Vieta E: Onset-age of bipolar disorders at six international sites. J Affect Disord 2010, 121(1-2):143-146.

99. Thompson KN, Conus PO, Ward JL, Phillips LJ, Koutsogiannis J, Leicester S, McGorry PD: The initial prodrome to bipolar affective disorder: prospective case studies. J Affect Disord 2003, 77(1):79-85.
100. Ostergaard SD, Straszek S, Petrides G, Skadhede S, Jensen SO, MunkJorgensen $\mathrm{P}$, Nielsen J: Risk factors for conversion from unipolar psychotic depression to bipolar disorder. Bipolar Disord 2014, 16(2):180-189.

101. El-Sayed M, Steen RG, Poe MD, Bethea TC, Gerig G, Lieberman J, Sikich L: Brain volumes in psychotic youth with schizophrenia and mood disorders. J Psychiatry Neurosci 2010, 35(4):229-236.

102. Gogtay N, Weisinger B, Bakalar JL, Stidd R, Fernandez de la Vega O, Miller R, Clasen L, Greenstein D, Rapoport JL: Psychotic symptoms and gray matter deficits in clinical pediatric populations. Schizophr Res 2012, 140(1-3):149-154.

103. Bombin I, Mayoral M, Castro-Fornieles J, Gonzalez-Pinto A, de la Serna E, Rapado-Castro M, Barbeito S, Parellada M, Baeza I, Graell M, Payá B, Arango C: Neuropsychological evidence for abnormal neurodevelopment associated with early-onset psychoses. Psychol Med 2013, 43(4):757-768.

104. Mico JA, Rojas-Corrales MO, Gibert-Rahola J, Parellada M, Moreno D, Fraguas D, Graell M, Gil J, Irazusta J, Castro-Fornieles J, Soutullo C, Arango C, Otero S, Navarro A, Baeza I, Martínez-Cengotitabengoa M, González-Pinto A: Reduced antioxidant defense in early onset first-episode psychosis: a case-control study. BMC Psychiatry 2011, 11:26.

105. Kelley R, Chang KD, Garrett A, Alegria D, Thompson P, Howe M, L Reiss A: Deformations of amygdala morphology in familial pediatric bipolar disorder. Bipolar Disord 2013, 15(7):795-802.

106. Elvsashagen T, Westlye LT, Boen E, Hol PK, Andersson S, Andreassen OA, Boye B, Malt UF: Evidence for reduced dentate gyrus and fimbria volume in bipolar II disorder. Bipolar Disord 2013, 15(2):167-176.

107. Elvsashagen T, Westlye LT, Boen E, Hol PK, Andreassen OA, Boye B, Malt UF: Bipolar II disorder is associated with thinning of prefrontal and temporal cortices involved in affect regulation. Bipolar Disord 2013, 15(8):855-864.

108. Mwangi B, Spiker D, Zunta-Soares GB, Soares JC: Prediction of pediatric bipolar disorder using neuroanatomical signatures of the amygdala. Bipolar Disord 2014, 16(7):713-721.

109. Kempton MJ, Geddes JR, Ettinger U, Williams SC, Grasby PM: Meta-analysis, database, and meta-regression of 98 structural imaging studies in bipolar disorder. Arch Gen Psychiatry 2008, 65(9):1017-1032.

110. Arnone D, Cavanagh J, Gerber D, Lawrie SM, Ebmeier KP, McIntosh AM: Magnetic resonance imaging studies in bipolar disorder and schizophrenia: meta-analysis. Br J Psychiatry 2009, 195(3):194-201.

111. McDonald C, Marshall N, Sham PC, Bullmore ET, Schulze K, Chapple B, Bramon E, Filbey F, Quraishi S, Walshe M, Murray RM: Regional brain morphometry in patients with schizophrenia or bipolar disorder and their unaffected relatives. Am J Psychiatry 2006, 163(3):478-487.

112. Zabala A, Rapado M, Arango C, Robles O, de la Serna E, Gonzalez C, Rodriguez-Sanchez JM, Andres P, Mayoral M, Bombin I: Neuropsychological functioning in early-onset first-episode psychosis: comparison of diagnostic subgroups. Eur Arch Psychiatry Clin Neurosci 2010, 260(3):225-233.

113. Kessing LV, Hansen HV, Hvenegaard A, Christensen EM, Dam H, Gluud C, Wetterslev J, Early Intervention Affective Disorders Trial G: Treatment in a specialised out-patient mood disorder clinic v. standard out-patient treatment in the early course of bipolar disorder: randomised clinical trial. Br J Psychiatry 2013, 202(3):212-219.

114. Kessing LV, Hansen HV, Christensen EM, Dam H, Gluud C, Wetterslev J, Early Intervention Affective Disorders Trial G: Do young adults with bipolar disorder benefit from early intervention? J Affect Disord 2014 152-154:403-408.

115. Paaren A, von Knorring $L$, Jonsson $U$, Bohman $H$, Olsson G, von Knorring AL: Drug prescriptions of adults with adolescent depression in a community sample. Pharmacoepidemiol Drug Saf 2012, 21(2):130-136.

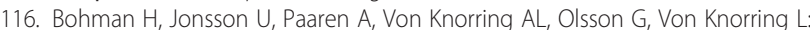
Long-term follow-up of adolescent depression. A population-based study. Ups J Med Sci 2010, 115(1):21-29.

117. Angst J, Gamma A, Benazzi F, Ajdacic V, Eich D, Rossler W: Toward a re-definition of subthreshold bipolarity: epidemiology and proposed criteria for bipolar-II, minor bipolar disorders and hypomania. J Affect Disord 2003, 73(1-2):133-146.

118. Geller B, Zimerman B, Williams M, Bolhofner K, Craney JL: Bipolar disorder at prospective follow-up of adults who had prepubertal major depressive disorder. Am J Psychiatry 2001, 158(1):125-127. 